\title{
A tailored computation of the mean dynamic topography for a consistent integration into ocean circulation models
}

\author{
S. Becker • M. Losch • J.M. Brockmann • G. Freiwald • W.-D. Schuh
}

Received: date / Accepted: date

\begin{abstract}
Geostrophic surface velocities can be derived from the gradients of the mean dynamic topographythe difference between the mean sea surface and the geoid. Therefore, independently observed mean dynamic topography data are valuable input parameters and constraints for ocean circulation models. For a successful fit to observational dynamic topography data, not only the mean dynamic topography on the particular ocean model grid is required, but also information about its inverse covariance matrix. However, the calculation of the mean dynamic topography from satellite based gravity field models and altimetric sea surface height measurements is not straightforward. For this purpose, we previously developed an integrated approach to combining these two different observation groups in a consistent way without using the common filter approaches (Becker et al, 2012; Becker, 2012). Within this combination method the full spectral range of the observations is considered. Further, it allows the direct determination of the normal equations (i.e. the inverse of the error covariance matrix) of the mean dynamic topography on arbitrary grids, which makes it
\end{abstract}

S. Becker · J.M. Brockmann · W.-D. Schuh

University of Bonn

Institute of Geodesy and Geoinformation

Department of Theoretical Geodesy

Nussallee 17, D-53115 Bonn

Tel.: +49-228-733578

Fax: +49-228-736486

E-mail: silvia.becker@uni-bonn.de

M. Losch and G. Freiwald

Alfred Wegener Institute, Helmholtz Centre for Polar and Marine Research

Postfach 120161, D-27515 Bremerhaven

Tel.: +49-471-48311772

Fax: +49-471-48311797

E-mail: martin.losch@awi.de best suitable for ocean data assimilation. Meanwhile, we made significant improvements regarding the used data sets. In this paper we focus on the preprocessing steps of along-track altimetry data from Jason-1 and Envisat to obtain a mean sea surface profile. During this procedure a rigorous variance propagation is accomplished, so that, for the first time, the full covariance matrix of the mean sea surface is available. The combination of the mean profile and a combined GRACE/GOCE gravity field model yields a mean dynamic topography model for the North Atlantic Ocean that is characterized by a defined set of assumptions. We show that including the geodetically derived mean dynamic topography with the full error structure in a 3D stationary inverse ocean model improves modeled oceanographic features over previous estimates.

Keywords Mean dynamic topography . Ocean circulation · Altimetry · Gravity field · Consistent combination

\section{Introduction}

The ocean's mean dynamic topography (MDT) is the difference between the mean sea surface and the geoid. The MDT reflects many characteristics of the general ocean circulation. Therefore, independent estimates of the MDT have the potential to greatly improve ocean circulation estimates when properly combined with an ocean model.

The calculation of the mean dynamic topography, however, is not straightforward. While the sea surface can be directly observed by satellite altimeters, the satellite based determination of the Earth's gravity field and accordingly the geoid requires different measurement principles. The altimetric observations are given 
as point values or mean values over the footprint of the radar signal along the satellite ground track over the ocean. The along-track sample rate is very high, so that the altimetric measurements contain information with high spatial resolution along the repeating tracks. In contrast, the gravity field is usually represented by a band-limited series of spherical harmonic functions so that the spatial resolution of gravity field models is much coarser. As a result of these different respresentations and resolutions, the direct computation of the mean dynamic topography as the pointwise difference between sea surface heights and geoid heights does not lead to satisfactory results. Usually, dedicated filter approaches are introduced to overcome this difficulty and to homogenize all available information with respect to a common subspace (e.g. Bingham et al, 2008; Bosch and Savcenko, 2010; Rio et al, 2011; Knudsen et al, 2011). All derived statements are only valid in this subspace. The amount of signal loss in such procedures remains unclear. In addition, the proper integration of the MDT into an inverse ocean model not only requires the MDT itself on the particular ocean model grid but also reliable error estimates in terms of the (inverse) covariance matrix. This matrix is used in inverse ocean models to weight the model data differences in a least-squares sense. Propagated errors of a MDT model resulting from applying the common filter approaches, however, only represent the modeled part of the signals (commission error). The omitted or truncated part of the signal also ought to be taken into account to form a consistent model (Losch et al, 2002).

In our recently developed integrated approach the different pieces of information of gravity field models and altimetry are combined in a consistent way without using the common filter approaches (Becker et al, 2012; Becker, 2012; Becker et al, 2013). To provide reliable error estimates of the mean dynamic topography, the appropriate variance/covariance information of the included observations is required. Here, we focus on preprocessing the altimetric observations with a rigorous error propagation from the measurements to the derived profile of mean sea surface heights. Further, a rigorous variance component estimation determines relative weights between the observation groups and provides an optimal estimation of the mean dynamic topography.

This paper is organized as follows. Section 2 addresses the preprocessing steps of the altimetric measurements from along-track sea surface heights to a mean profile with a rigorous variance propagation. The method to incorporate a mean dynamic topography model into the inverse ocean model IFEOM and the integrated approach to estimate such a mean dynamic topography from altimetry and gravity field information along with its full covariance matrix as well as the particularly defined model configuration is described in section 3. The obtained results for the geodetic mean dynamic topography and its error description as well as its integration into the ocean circulation model are shown in section 4 . The paper closes with a discussion in section 5 .

\section{Preprocessing the altimetric data}

We use mono-mission along-track data sets to derive a profile of mean sea surface heights along with its full variance/covariance information for the North Atlantic Ocean. Along-track sea surface heights reduced by geophysical and range corrections including tides are provided by AVISO (http://www.aviso.oceanobs.com/ index.php?id=1267) for several satellite missions. We use observations from Jason-1 and Envisat because these two missions observed the sea surface simultaneously for a long time and the spatial resolution of the combined observations is sufficient for our purposes. Jason-1 was launched in December 2001 and Envisat in March 2002. Both satellites assumed an orbit with a repeating ground track. The ground track separation at the equator is $315 \mathrm{~km}$ for Jason-1 and $80 \mathrm{~km}$ for Envisat with a repeat cycle of approximately 10 days and 35 days respectively and an inclination of $66^{\circ}$ and $98.55^{\circ}$. We use corrected sea surface heights for the time period between October 2002 (first available data of Envisat) and February 2009 (orbit change of Jason-1). The alongtrack sample rate of the corrected sea surface heights is $1 \mathrm{~Hz}$.

This section describes the individual processing steps from the along-track sea surface height measurements of Jason-1 and Envisat to a combined mean profile including a rigorous error propagation. Figure 1 summarizes the accomplished procedure (Becker, 2012).

\subsection{Stochastic modeling}

Initially, the error of a single altimetric measurement and the correlations of the signal along the satellite ground tracks are empirically modeled based on a crossover analysis of the observations to enable a rigorous error propagation from the initial observations to the final product. For this purpose we consider the corrected sea surface heights as a statistically stationary time series; that is, the expectation as well as the variance of the signal is constant over time and the autocorrelations only depend on the time lags between the observations. 


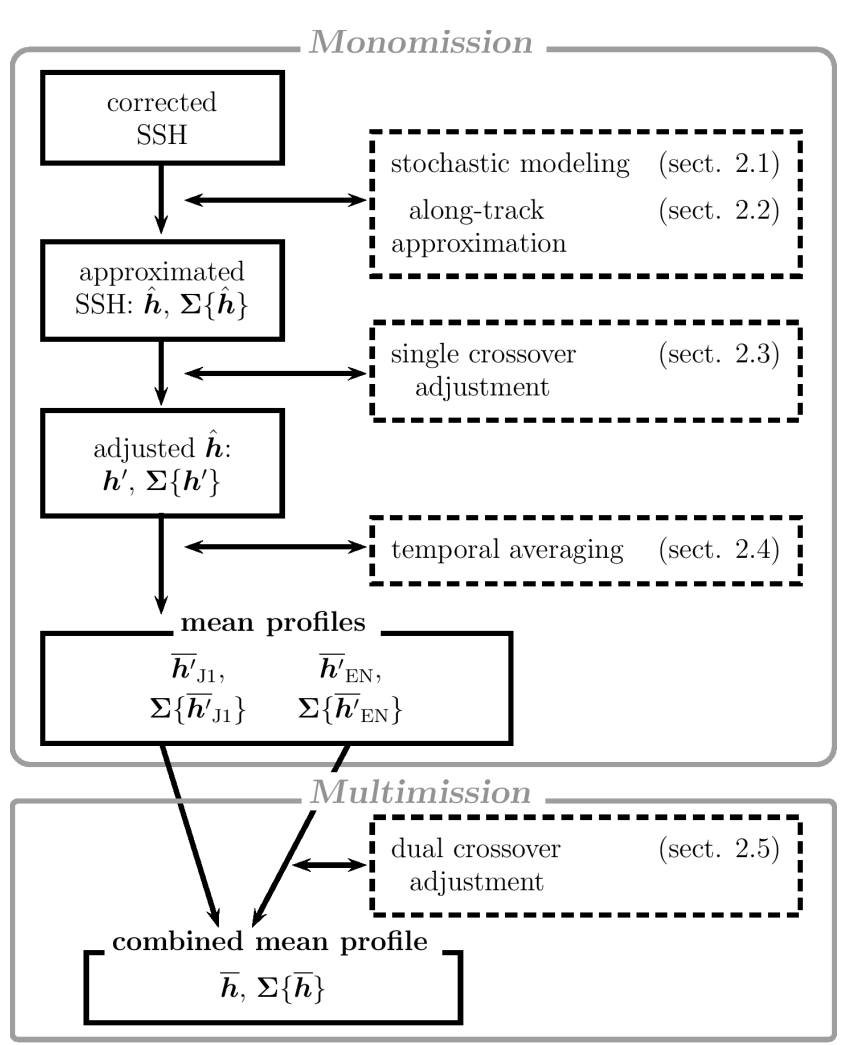

Fig. 1 Overview over individual processing steps from corrected sea surface heights ( $\mathrm{SSH}$ ) of Jason-1 and Envisat to the combined mean profile including its full covariance matrix.

\subsubsection{Analysis of crossover differences}

We analyse single crossover differences to assess the accuracy of an altimetric measurement; that is, we analyse the differences of sea surface heights for ascending and descending passes that intersect at crossover locations for a single satellite mission within one repeat cycle. The root mean square (RMS) of the crossover differences for the individual repeat cycles are calculated to derive the order of magnitude of the error of a single altimetric observation. The RMS varies on annual timescales linked to variations in the sea ice cover. Furthermore, not only do the crossover differences reflect the measurement errors but also the ocean variability. To obtain stationarity, we exclude crossover differences in areas of high latitudes $\left(>60^{\circ}\right)$ and those derived from observations with a time delay greater than two days in our computations. In addition, we do not use crossover differences in shallow water areas (bathymetry $\geq-1000 \mathrm{~m}$ ) or in areas with high ocean variability $(>0.2 \mathrm{~m})$. On average approximately 1,700 crossover differences out of 7,500 are used to compute the RMS values for Jason-1 and 3,200 out of 43,000 for Envisat. The mean of the cycle per cycle RMS of selected crossover differences, representing the standard deviation $\sigma_{\text {xo }}$ of a sea surface height difference, is used to estimate the standard deviation $\sigma_{\text {ssh }}$ of a single sea surface height measurement

$\sigma_{\mathrm{ssh}}=\frac{1}{\sqrt{2}} \sigma_{\mathrm{xo}}$.

This procedure yields a standard deviation of $3.39 \mathrm{~cm}$ for Jason-1 and $3.28 \mathrm{~cm}$ for Envisat, which agrees with the accuracy of a corrected sea surface height of $3.3 \mathrm{~cm}$ as stated in AVISO (2008).

\subsubsection{Correlations}

In order to model the correlations between the observations, we consider the sea surface heights along the satellite ground tracks as a time series. The resulting empirical autocorrelation function depends only on the temporal distance between the observations. Initially, the sea surface heights are reduced by a trend function. In general, the choice of the trend function is arbitrary. Here, we use the mean sea surface model CLS01 (Hernandez and Schaeffer, 2001). This model provides values directly at the observation points along with the corrected sea surface heights. After the trend reduction we assume the expectation value of the residual signal to be zero - satisfying the stationarity condition of a constant expectation value. The empirical autocorrelation function depends on the temporal distance $\Delta t$ and is computed based on the remaining signal. The autocorrelation function shows a fast decrease for both missions Jason-1 and Envisat with a halfwidth of approximately $20 \mathrm{~s}$ and is modeled by a linear combination of two exponential functions with the coefficients $a_{1}, a_{2}$, $b_{1}$ and $b_{2}$

$C(\Delta t)=a_{1} e^{-b_{1} \Delta t}+a_{2} e^{-b_{2} \Delta t}$.

Finally, the covariances of the altimetric observations are computed by rescaling the resulting correlation functions with the particular variance $\sigma_{\text {ssh }}^{2}$ derived by the crossover analysis. In this way, the covariance matrix of the along-track corrected sea surface heights can be assembled as required by the following processing step.

\subsection{Along-track approximation of sea surface heights}

Initially, we approximate the sea surface height measurements of the individual repeat cycles of Jason-1 and Envisat on so-called reference points along a mean ground track. This procedure provides time series of sea surface heights for the considered observational period at the particular reference points allowing for time averaging. The measurements of each repeat cycle are 
again considered as a time series. These time series are approximated by one-dimensional piecewise cubic polynomials, which form a continuous and continuously differentiable function. We use a remove/restore technique so that the reconstruction of the signal is guaranteed. The original sea surface heights are initially reduced by the mean sea surface model CLS01. The remaining signal is approximated along the satellite ground tracks in a least-squares adjustment. Note, that the empirical autocovariance or the autocorrelation function that is used to derive the covariance matrix of the sea surface heights which is required in the least-squares estimation is computed based on the same residual signal rendering the methodology consistent.

The observations of each repeat cycle are divided into sections. First, the initial partition is defined by the coastlines. These sections are then divided again, so that each subsection contains a time series of reduced observations without data gaps. These time series are assumed to be uncorrelated with each other and consequently, treated individually. This assumption is reasonable because measurements which are separated by land areas or time can be considered as independent from each other. The final subsections are approximated by piecewise cubic polynomials. Denoting the resulting parameters that describe the residual signal with $\boldsymbol{x}$, the matrix containing the functional relation with $\boldsymbol{A}$ and the previously subtracted mean sea surface with $\mathbf{M S S}_{\mathrm{CLS} 01}$, the sea surface heights along a mean ground track can be written as

$\hat{\boldsymbol{h}}=\boldsymbol{A} \boldsymbol{x}+\mathbf{M S S}_{\mathrm{CLS} 01}$.

Within the approximation procedure a rigorous error propagation is accomplished yielding the covariance matrix $\boldsymbol{\Sigma}\{\boldsymbol{x}\}$ of the estimated parameters and in a next step the covariance matrix $\boldsymbol{\Sigma}\{\hat{\boldsymbol{h}}\}$ of the approximated sea surface heights. Note, that these are only correlated within one subsection of a particular repeat cycle.

\subsection{Single crossover adjustment}

In the next processing step the single crossovers within one repeat cycle are adjusted to minimize radial errors and the impact of the ocean variability on the determination of mean sea surface heights. For this purpose the estimated parameters $\boldsymbol{x}$ of the previous step are considered as the result of the first step in a twostage least squares adjustment with restrictions (see e.g. Koch, 1999, chapter 3.2.7). In the following, we constrain the parameters, so that the single crossover differences within one repeat cycle become zero

$\hat{\boldsymbol{h}}_{\mathrm{asc}}^{\mathrm{xo}}-\hat{\boldsymbol{h}}_{\mathrm{desc}}^{\mathrm{xo}}=\boldsymbol{B}_{\mathrm{asc}}^{T} \boldsymbol{x}-\boldsymbol{B}_{\mathrm{desc}}^{T} \boldsymbol{x} \stackrel{!}{=} \mathbf{0}$ with the sea surface height $\hat{\boldsymbol{h}}_{\text {asc }}^{\text {xo }}=\boldsymbol{B}_{\text {asc }}^{T} \boldsymbol{x}$ at the crossover of the ascending pass and $\hat{\boldsymbol{h}}_{\mathrm{desc}}^{\text {xo }}=\boldsymbol{B}_{\mathrm{desc}}^{T} \boldsymbol{x}$ of the descending pass in which the matrices $\boldsymbol{B}_{\text {asc }}^{T}$ and $\boldsymbol{B}_{\text {desc }}^{T}$ connect the parameters $\boldsymbol{x}$ with the sea surface heights. The estimated parameters $\boldsymbol{x}$ of the first step consequently represent (pseudo-)observations for the second step of the least squares estimation - the adjustment with conditions. This leads to the final parameters $\overline{\boldsymbol{x}}$ and its covariance matrix $\boldsymbol{\Sigma}\{\overline{\boldsymbol{x}}\}$. Finally, the sea surface heights $\boldsymbol{h}^{\prime}$ along the mean ground tracks and the covariance matrices $\boldsymbol{\Sigma}\left\{\boldsymbol{h}^{\prime}\right\}$ are calculated based on these results (in analogy to eq. (3)). Due to the restrictions on the parameters the different sections of the repeat cycles are no longer uncorrelated. Correspondingly, the covariance matrices $\boldsymbol{\Sigma}\left\{\boldsymbol{h}^{\prime}\right\}$ are not sparse and their evaluation is expensive.

\subsection{Temporal averaging}

The resulting time series of sea surface heights at the reference points along the mean ground tracks contain both non-periodic and periodic parts due to ocean variability. As we are interested in the time-averaged sea surface of the non-periodic signal, we tested the influence of periodic parts on the determination of the temporal average by modeling an annual and seasonal signal. In general, periodic parts do not influence the determination of the mean when a signal with periodic components is observed with a constant time-lag over complete cycles. In this study, we use approximately six full annual cycles of observations, so that the impact of the periodic parts on the determination of the mean values is small and can be neglected. Consequently, we derive time-averaged sea surface height profiles $\overline{\boldsymbol{h}}_{\mathrm{J} 1}$ and $\overline{\boldsymbol{h}^{\prime}}$ EN for Jason-1 and Envisat and the corresponding covariance matrices $\boldsymbol{\Sigma}\left\{{\overline{\boldsymbol{h}^{\prime}}}_{\text {J1 }}\right\}$ and $\boldsymbol{\Sigma}\left\{{\overline{\boldsymbol{h}^{\prime}}}_{\text {EN }}\right\}$ based on the previously determined $\boldsymbol{h}^{\prime}$ at the reference points for each repeat cycle and their covariances $\boldsymbol{\Sigma}\left\{\boldsymbol{h}^{\prime}\right\}$.

\subsection{Dual crossover adjustment}

The mean profiles derived from the two different satellite mission observations must be adjusted before merging the two data sets. Systematic differences due to, for example, different orbits and different range and geophysical corrections have to be removed. These relative range biases between Jason-1 and Envisat can be obtained by analysing the differences of the mean sea surface heights at dual crossovers. We do not adjust one mission with respect to the other, but determine corrections for both missions. We require that the mean 


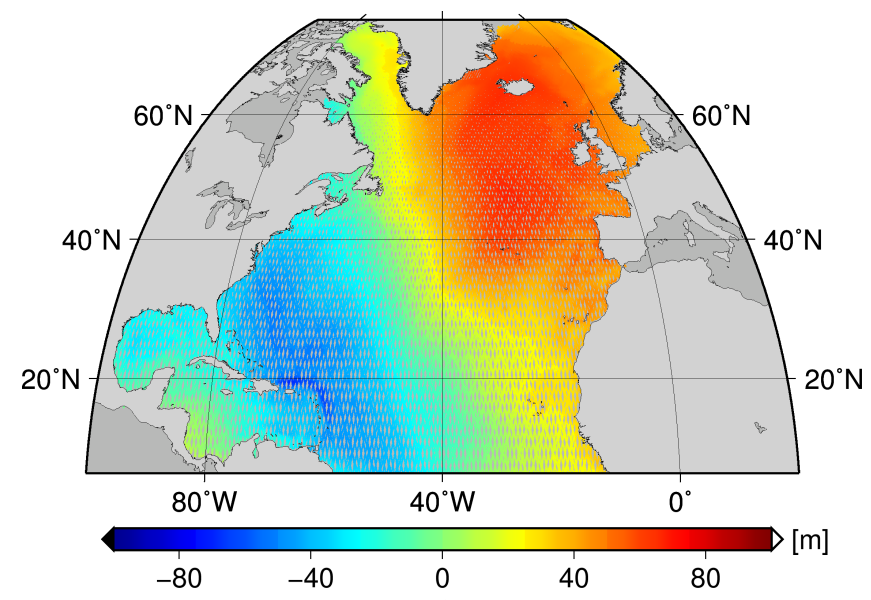

(a)

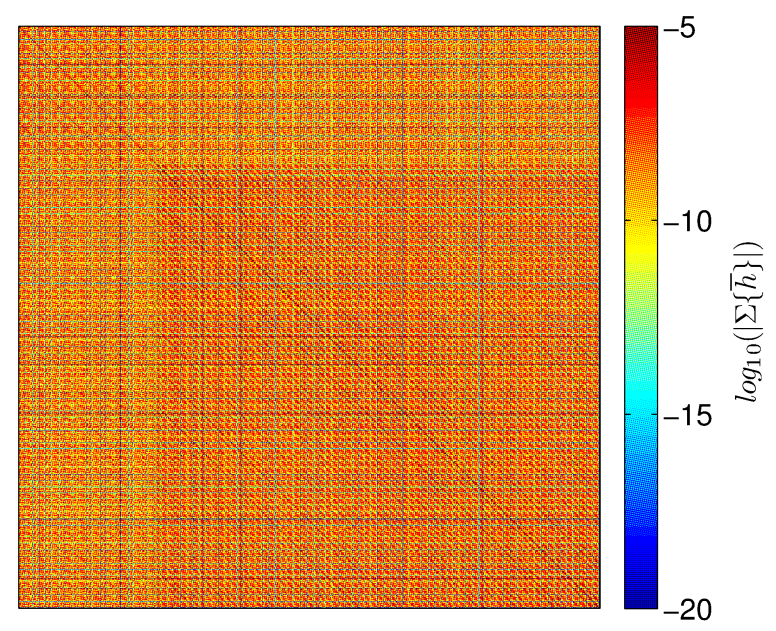

(b)

Fig. 2 Mean combined profile $\overline{\boldsymbol{h}}$ and its corresponding covariance matrix $\Sigma\{\overline{\boldsymbol{h}}\}$.

sea surface heights at dual crossovers $d x o$ are identical

${\overline{\boldsymbol{h}^{\prime}}}_{\mathrm{J} 1}^{\mathrm{dxo}}-{\overline{\boldsymbol{h}^{\prime}}}_{\mathrm{EN}}^{\mathrm{dxo}} \stackrel{!}{=} \mathbf{0}$.

To satisfy this condition, we determine the corrections $\boldsymbol{b}_{\mathrm{J} 1}^{\mathrm{dxo}}$ and $\boldsymbol{b}_{\mathrm{EN}}^{\mathrm{dxo}}$ at the dual crossovers of Jason-1 and Envisat. These quantities and their covariance matrix $\Sigma_{\mathrm{b}}^{\mathrm{dxo}}$ result from an adjustment with condition equations (see e.g. Koch, 1999, chapter 3.5.5) taking into account the covariance matrices of the mean sea surface at dual crossovers $\boldsymbol{\Sigma}\left\{{\overline{\boldsymbol{h}^{\prime}}}_{\text {J1 }}^{\mathrm{dxo}}\right\}$ and $\boldsymbol{\Sigma}\left\{{\overline{\boldsymbol{h}^{\prime}}}_{\mathrm{EN}}^{\mathrm{dxo}}\right\}$. In order to obtain the required corrections at the remaining reference points, we linearly interpolate the corrections along the satellite ground tracks paying special attention to the error propagation. For latitudes, where only Envisat observations are available (latitudes $>66^{\circ} \mathrm{N}$ ) and accordingly no dual crossovers, we apply the mean estimated correction as an approximate value to adjust the Envisat observations. Since there is no information about the differences between Jason-1 and Envisat measurements in this area, the uncertainty of this correction is increased to account for this drawback. We empirically chose to use twice the mean standard deviation of the estimated corrections.

\subsection{Combined mean profile}

Finally, the two mean profiles can be combined by adding the particular correction

$\overline{\boldsymbol{h}}=\left[\begin{array}{c}\overline{\boldsymbol{h}^{\prime}} \\ \overline{\mathrm{J}}^{\prime} \\ \mathrm{EN}\end{array}\right]+\left[\begin{array}{c}\boldsymbol{b}_{\mathrm{J} 1} \\ \boldsymbol{b}_{\mathrm{EN}}\end{array}\right]$.

The corrections are correlated to the mean sea surface profiles and they are not error-free. Thus, the overall covariance matrix of the mean profile results from

$$
\boldsymbol{\Sigma}\{\overline{\boldsymbol{h}}\}=\boldsymbol{\Sigma}\left\{\overline{\boldsymbol{h}^{\prime}}\right\}+\boldsymbol{\Sigma}\left\{\overline{\boldsymbol{h}^{\prime}}, \boldsymbol{b}\right\}+\boldsymbol{\Sigma}\left\{\boldsymbol{b}, \overline{\boldsymbol{h}^{\prime}}\right\}+\boldsymbol{\Sigma}\{\boldsymbol{b}\}
$$

with the covariance matrix of the monomission mean profiles $\boldsymbol{\Sigma}\left\{\overline{\boldsymbol{h}^{\prime}}\right\}$, the matrices $\boldsymbol{\Sigma}\left\{\overline{\boldsymbol{h}^{\prime}}, \boldsymbol{b}\right\}$ and $\boldsymbol{\Sigma}\left\{\boldsymbol{b}, \overline{\boldsymbol{h}^{\prime}}\right\}$ containing the correlations between the mean profiles and the corrections and the covariance matrix of the corrections $\boldsymbol{\Sigma}\{\boldsymbol{b}\}$.

Figure 2 shows the combined mean profile that runs through the North Atlantic Ocean and the corresponding covariance matrix.

\section{Model setup}

\subsection{Inverse ocean modeling - IFEOM}

The Inverse Finite Element Ocean Model (IFEOM) is an inverse ocean model configured for the North Atlantic Ocean between $4.5^{\circ} \mathrm{N}$ and $78^{\circ} \mathrm{N}$ (Sidorenko, 2004; Richter, 2010). The model is based on the stationary primitive equations for the ocean. Solutions to these equations are found by minimizing the cost function

$J=\frac{1}{2} \sum_{i} J_{i} \stackrel{!}{=} \min$

subject to stationary balances of ocean momentum, mass, energy (potential temperature), and salt. $J_{i}, i=1,2, \ldots$. are the different contributions to $J$. Energy and salt conservation are treated in a weak sense, that is, allowing small residuals to account for model approximations such as stationarity and grid resolution, but momentum and mass conservation are enforced exactly as strong 
constraints. The cost function (8) contains contributions from quadratic model-data differences (temperature and salinity from a hydrographic atlas and mean dynamic topography) weighted by the inverses of their respective error covariances and prior information such as smoothness of the solution. Climatological salinity and temperature data of a hydrographic atlas on a $1^{\circ}$ grid (Gouretski and Koltermann, 2004) are used to constrain the ocean model IFEOM. The grid of the atlas was used to define the grid nodes of the finite element model (except near coastlines). The different cost function terms are weighted by the inverse of prior uncertainty estimates. For example, the hydrographic data terms are scaled by the annual variance of the observations. The resulting weights typically increase with depth where the ocean tends to be quiescent. Towards the open boundary at $4.5^{\circ} \mathrm{N}$, weights are increased in order to constrain the model solution to the first guess in the absence of better information.

In general, the error correlations of the observations are unknown a priori so that most covariances in eq. (8) reduce to diagonal matrices. As in Becker et al (2012), IFEOM is extended by taking into account the full inverse mean dynamic topography error covariances $\boldsymbol{\Sigma}\{\boldsymbol{\eta}\}^{-1}$ (or weight matrix $\boldsymbol{W}\{\boldsymbol{\eta}\}$ ) (Freiwald, 2012). The particular cost function contribution can be written as

$$
\begin{aligned}
J_{\boldsymbol{\eta}} & =\left(\boldsymbol{\eta}_{\text {data }}-\boldsymbol{\eta}_{\text {model }}\right)^{T} \boldsymbol{W}\{\boldsymbol{\eta}\}\left(\boldsymbol{\eta}_{\text {data }}-\boldsymbol{\eta}_{\text {model }}\right) \\
& =\left(\boldsymbol{\eta}_{\text {data }}-\boldsymbol{\eta}_{\text {model }}\right)^{T} \boldsymbol{\Sigma}\{\boldsymbol{\eta}\}^{-1}\left(\boldsymbol{\eta}_{\text {data }}-\boldsymbol{\eta}_{\text {model }}\right)
\end{aligned}
$$

with the "observed" data $\boldsymbol{\eta}_{\text {data }}$ derived from gravimetry and altimetry and their modeled counterparts $\boldsymbol{\eta}_{\text {model }}$. The estimation procedure requires the inverse of the variance/covariance matrix $\boldsymbol{\Sigma}\{\boldsymbol{\eta}\}$ to compute the weighting matrix $\boldsymbol{W}\{\boldsymbol{\eta}\}$ for the model-data misfit. The following section describes how the mean dynamic topography $\boldsymbol{\eta}_{\text {data }}$ and its inverse covariance matrix is determined.

\subsection{Estimation of a geodetic mean dynamic topography}

The two different observation groups, namely the gravity field information and the altimetric mean sea surface, are combined in terms of normal equations. For this purpose the altimetric observations are considered as the sum of geoid heights and the mean dynamic topography. The geoid is parameterized by spherical harmonics. The MDT is represented by a linear combination of finite element basis functions. The nodal points of the finite elements are defined by the particular ocean model grid - in this case the IFEOM grid. Here, we use two-dimensional linear piecewise polynomials as basis functions so that the unknowns are directly the mean dynamic topography at the nodal points. Summarizing the spherical harmonic coefficients in the vector of unknowns $\boldsymbol{x}_{\mathrm{cs}}$ and the mean dynamic topography parameters in $\boldsymbol{x}_{\mathrm{FE}}\left(=\boldsymbol{\eta}_{\text {data }}\right)$, the observation equations for the altimetric information can be written as

$\boldsymbol{l}_{\mathrm{A}}+\boldsymbol{v}_{\mathrm{A}}=\left[\begin{array}{ll}\boldsymbol{A}_{\mathrm{cs}} & \boldsymbol{A}_{\mathrm{FE}}\end{array}\right]\left[\begin{array}{c}\boldsymbol{x}_{\mathrm{cs}} \\ \boldsymbol{x}_{\mathrm{FE}}\end{array}\right]$

with the observations $\boldsymbol{l}_{\mathrm{A}}$, the corrections $\boldsymbol{v}_{\mathrm{A}}$ and the matrices $\boldsymbol{A}_{\mathrm{cs}}$ and $\boldsymbol{A}_{\mathrm{FE}}$ connecting the parameters to the observations. The vector of the unknown gravity field parameters $\boldsymbol{x}_{\mathrm{cs}}$ is split into frequency subdomains to describe the different frequency bands of the observations along with their accuracy. The accuracy of the gravity field models decreases with increasing spherical harmonic degree. The altimetric observations are here restricted to the North Atlantic Ocean and therefore determine only part of the frequency spectrum; i.e. the long wavelengths cannot be determined from the altimetric observations. Therefore, we introduce smoothness conditions according to the Hilbert Space $H_{\Gamma}^{1}$ (Schuh and Becker, 2010; Schuh et al, 2013). We use Kaula's rule of thumb (Kaula, 1966) as a priori information to constrain the size of the unknown coefficients. Additionally, the omission domain is parameterized within the altimetric observation equations based on a priori information to accomplish a complete modeling of the observations.

The different observation groups are combined according to the summation theorem of normal equations. The combined normal equations can be written as

$$
\left[\begin{array}{cc}
\boldsymbol{N}_{\mathrm{cs}}^{\mathrm{G}}+\boldsymbol{N}_{\mathrm{cs}}^{\mathrm{A}}+\boldsymbol{N}_{\mathrm{cs}}^{\mathrm{S}} & \boldsymbol{N}_{\mathrm{cs}, \mathrm{FE}}^{\mathrm{A}} \\
\boldsymbol{N}_{\mathrm{FE}, \mathrm{cs}}^{\mathrm{A}} & \boldsymbol{N}_{\mathrm{FE}}^{\mathrm{A}}
\end{array}\right]\left[\begin{array}{c}
\boldsymbol{x}_{\mathrm{cs}} \\
\boldsymbol{x}_{\mathrm{FE}}
\end{array}\right]=\left[\begin{array}{c}
\boldsymbol{n}_{\mathrm{cs}}^{\mathrm{G}}+\boldsymbol{n}_{\mathrm{cs}}^{\mathrm{A}} \\
\boldsymbol{n}_{\mathrm{FE}}^{\mathrm{A}}
\end{array}\right]
$$

with the particular components of the gravity field $(\mathrm{G})$, the altimetric observations (A) and the smoothness conditions $(\mathrm{S})$. A reduction of the gravity field parameters from these normal equations directly provides the normal equations of the mean dynamic topography $\boldsymbol{\eta}_{\text {data }}(=$ $\boldsymbol{x}_{\mathrm{FE}}$ ) on the ocean model grid

$$
\begin{aligned}
\left(\boldsymbol{N}_{\mathrm{FE}}^{\mathrm{A}}-\boldsymbol{N}_{\mathrm{FE}, \mathrm{cs}}^{\mathrm{A}} \boldsymbol{N}_{\mathrm{cs}}^{-1} \boldsymbol{N}_{\mathrm{cs}, \mathrm{FE}}^{\mathrm{A}}\right) \boldsymbol{x}_{\mathrm{FE}} & =\left(\boldsymbol{n}_{\mathrm{FE}}^{\mathrm{A}}-\boldsymbol{N}_{\mathrm{FE}, \mathrm{cs}}^{\mathrm{A}} \boldsymbol{N}_{\mathrm{cs}}^{-1} \boldsymbol{n}_{\mathrm{cs}}\right) \\
\overline{\boldsymbol{N}}_{\mathrm{FE}} \boldsymbol{x}_{\mathrm{FE}} & =\overline{\boldsymbol{n}}_{\mathrm{FE}} \\
\boldsymbol{\Sigma}\{\boldsymbol{\eta}\}^{-1} \boldsymbol{x}_{\mathrm{FE}} & =\overline{\boldsymbol{n}}_{\mathrm{FE}}
\end{aligned}
$$

with $\boldsymbol{N}_{\mathrm{cs}}=\boldsymbol{N}_{\mathrm{cs}}^{G}+\boldsymbol{N}_{\mathrm{cs}}^{A}+\boldsymbol{N}_{\mathrm{cs}}^{S}$. Note, that the normal equation matrix $\overline{\boldsymbol{N}}_{\mathrm{FE}}$ directly provides the inverse covariance matrix $\boldsymbol{\Sigma}\{\boldsymbol{\eta}\}^{-1}$ required by the ocean model 
(see equation (9)) because the parameters $\boldsymbol{x}_{\mathrm{FE}}$ represent directly the mean dynamic topography $\boldsymbol{\eta}_{\text {data }}$ at the nodal points of the finite elements.

The model is derived and described in more detail in Becker et al (2012) and Becker (2012).

\subsubsection{Relative weighting - variance component estimation}

To provide an optimal estimation of the mean dynamic topography parameters, relative weights between the different observation groups play an important role. The shorthand version of the combined normal equations (11)

$$
\left(\boldsymbol{N}^{\mathrm{G}}+\boldsymbol{N}^{\mathrm{A}}+\boldsymbol{N}^{\mathrm{S}}\right) \boldsymbol{x}=\boldsymbol{n}^{\mathrm{G}}+\boldsymbol{n}^{\mathrm{A}}
$$

is rewritten as

$$
\left(\sum_{i} \frac{1}{\sigma_{i}^{2}} \boldsymbol{N}^{i}\right) \boldsymbol{x}=\sum_{i} \frac{1}{\sigma_{i}^{2}} \boldsymbol{n}^{i}
$$

for the three observation groups $i=\mathrm{G}, \mathrm{A}, \mathrm{S}$. As a new feature, the optimal relative weights $1 / \sigma_{i}^{2}$ are determined via a rigorous variance component estimation (see e.g. Koch and Kusche, 2002; Brockmann and Schuh, 2010) in contrast to the previous studies presented in Becker et al (2012) and Becker (2012).

\subsubsection{Specific configuration}

The results shown below are obtained with the following model configuration. In this study, we make use of the static part of the GRACE gravity field model ITG-Grace2010 (Mayer-Gürr et al, 2010) and the GOCE gravity field model GOCE_EGM_TIMrelease3 (Pail et al, 2011) derived by the time-wise approach. Of these two satellite-only gravity field models, the first one is expanded as a sum of spherical harmonics up to degree and order 180 while the latter has a maximum degree of 250. Both gravity field models are available with the full covariance matrix of the potential coefficients so that their normal equations can be reconstructed. We use the combined ITG-Grace2010 and GOCE_EGM_TIMreleas normal equations.

For the altimetric information we use the normal equations for the obtained mean sea surface profile of Jason-1 and Envisat (section 2.6). The commission domain spans the spherical harmonics of degree 2-300. The omission domain is modeled by a priori information from the high-degree gravity field model EGM2008 (Pavlis et al, 2012) for the degrees 301-2160 and Kaula's rule of thumb (Kaula, 1966) for degrees $>2160$. That is the expectation $E\{S\}$ of the high-frequency signal is assumed to be zero and its covariances are determined by the signal degree variances of EGM2008 and the degree variances of Kaula's rule in the particular frequency domain based on a homogeneous, isotropic covariance function on the sphere. The additional smoothness conditions are added for degrees between 180 and 300. The nodal points of the finite elements are predefined by the regular triangulated $1^{\circ} \times 1^{\circ}$ grid of IFEOM. As mentioned above, we use linear piecewise polynomials as basis functions to represent the mean dynamic topography on the finite element grid.

\section{Results}

4.1 Geodetic mean dynamic topography

The resulting estimated MDT (called ITG_MDT in the following) and its associated standard deviations (squareroot of the diagonal elements of the error covariance matrix) on the $1^{\circ} \times 1^{\circ}$ grid are shown in figure 3 . The mean dynamic topography contains non-physical short scale features. In general, the standard deviation increases with increasing latitude. A temporary decrease can be observed at latitudes around $66^{\circ} \mathrm{N}$ where the included altimetric observations are densest. Beyond latitude $66^{\circ} \mathrm{N}$ only Envisat observations are available. Large standard deviations are also observed at the boundaries, where the separation of the mean sea surface into geoid and MDT is most challenging. On average, the standard deviation is $16.2 \mathrm{~cm}$.

Closed-loop simulations have shown that the altimetry signal can be separated very well into the geoid and mean dynamic topography when the spatial resolution of the finite elements matches the frequency band for which the information content of the gravity field is very accurate (Becker, 2012). Under these circumstances the estimated MDT is smooth. Whenever the spatial resolution of the finite elements is higher than the resolution of sufficiently accurate gravity field information, as in seaur case, non-physical oscillations occur. The characteristics of the mean dynamic topography, however, are reflected by the particular associated error description and our method yields a consistent variance/covariance matrix in both cases. In figure 3, the field of standard deviations reflects the noisy patterns of the MDT. Further, the spatial resolution of the finite elements increases at high latitudes so that the non-physical noise is amplified along with an increase of the standard deviations. 


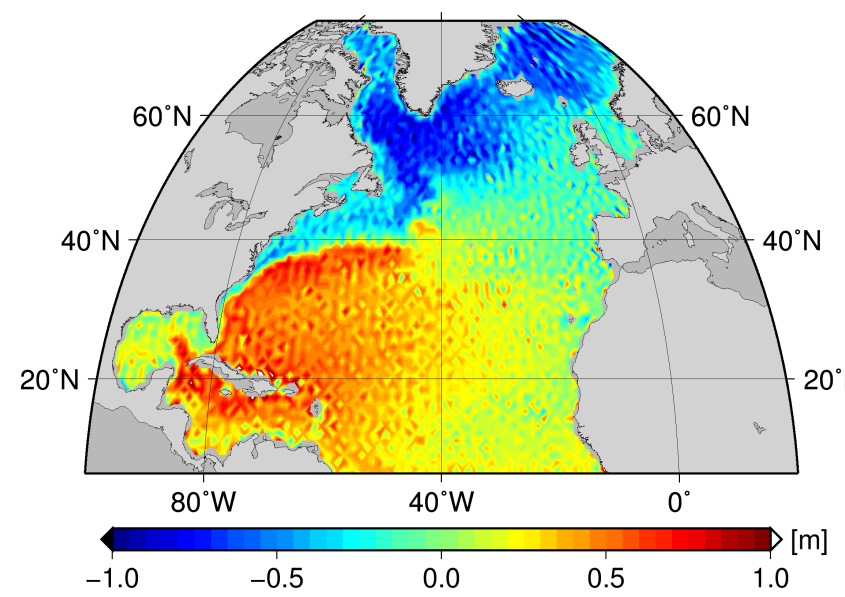

(a)

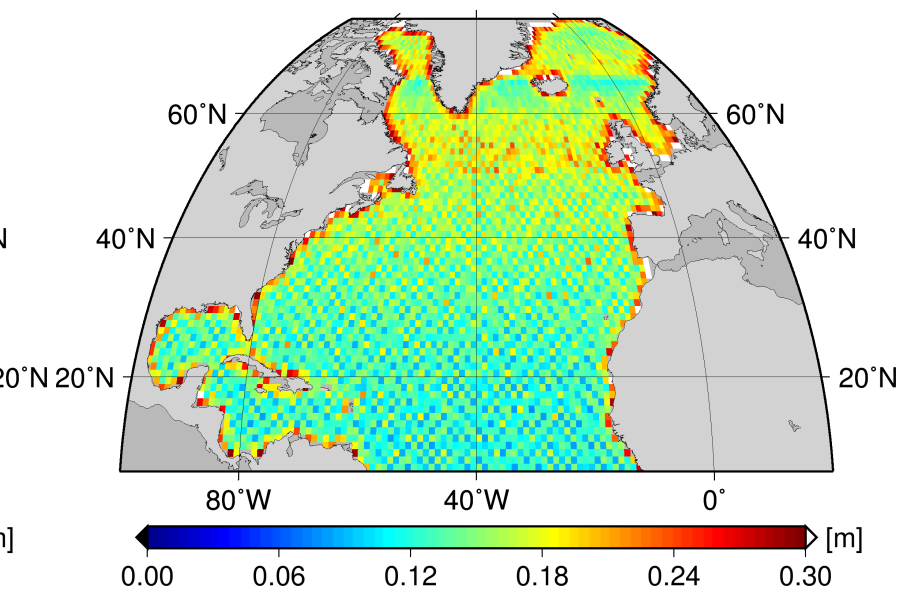

(b)

Fig. 3 Estimated geodetic mean dynamic topography ITG_MDT and the corresponding standard deviations.

Table 1 Progression of relative weights $1 / \sigma_{i}^{2}$ for the different observation groups.

\begin{tabular}{lcccccc}
\hline iteration & 0 & 1 & 2 & 3 & 4 & 5 \\
\hline GRACE & 1.000 & 1.000 & 0.9997 & 0.9999 & 0.9998 & 0.9998 \\
GOCE & 1.000 & 0.9999 & 0.9999 & 0.9999 & 0.9999 & 0.9999 \\
Altimetry & 1.000 & 0.6502 & 0.6482 & 0.6484 & 0.6484 & 0.6484 \\
Smoothness & 1.000 & 0.7760 & 0.7440 & 0.7377 & 0.7365 & 0.7362 \\
\hline
\end{tabular}

\subsubsection{Relative weights}

Table 1 shows the progression of the relative weights of the different observation groups during the iterative variance component estimation process (see section 3.2.1). The weights of the GRACE and GOCE observations remain at approximately $1 / \sigma_{\mathrm{G}}^{2} \approx 1$, but the altimetric measurements and the smoothness conditions are downweighted. The decreasing weight of the pseudo-observations according to the smoothness conditions implies a larger impact of the real observations. The downweighting of the altimetric data indicates that the a priori assumed errors are too optimistic. The covariance matrix of the altimetric data is composed of two terms - the covariance of the mean sea surface derived on the basis of empirical covariance functions (see section 2) and the covariance describing the omission domain based on the signal degree variances of the EGM2008 and the degree variances according to Kaula's rule. On average, the standard deviation of the altimetric information is $17.7 \mathrm{~cm}$ mostly consisting of the omission domain part. The relative weight of $w_{\mathrm{A}}=$ $1 / \sigma_{\mathrm{A}}^{2}=0.6484$ implies an error of the assumed a priori standard deviation of approximately $25 \%\left(1 / \sqrt{w_{\mathrm{A}}}\right)$. The crucial point certainly is the modeling of the omission error by using degree variances. Those only represent a global mean and may not be perfectly adequate to model the omission error over the North Atlantic Ocean, but this deficit is compensated by the variance component estimation. Besides, it can be expected, that the local altimetric observations are down weighted relative to the globally defined gravity field models with respect to estimate the Earth's global gravity field.

\subsubsection{Comparison to other models}

In the following, we compare the ITG_MDT model to other estimates of the mean dynamic topography: the CLS09 (Rio et al, 2011), DTU10 (Andersen and Knudsen, 2009) and Niiler (Maximenko et al, 2009) mean dynamic topography models. Figure 4 illustrates the different estimates for a profile along the meridian $44.5^{\circ} \mathrm{W}$. The non-physical oscillations in the ITG_MDT are apparent, but the large scale features agree mostly with the other estimates. The comparison models differ considerably from each other at the Mann eddy between the latitudes $40.5^{\circ} \mathrm{N}$ and $42.5^{\circ} \mathrm{N}$, where the ITG_MDT tends towards the CLS09 model in this area.

To evaluate the model agreement, we show the root mean square of the differences between the ITG_MDT and the three comparison models and the mean ratio of the absolute differences and standard deviations as 
Table 2 Mean standard deviation of estimated MDT $\sigma_{\mathrm{MDT}}$, root mean square of differences between the ITG_MDT, IFEOM_MDT and the CLS09, DTU10 as well as the Niiler model and the mean of relative differences $R_{I}$ (see text and equation (15)) for the overall study area and three profiles along different meridians. In addition, the root mean square of the particular differences between the three comparision models CLS09, DTU10 and Niiler are listed.

\begin{tabular}{llcccccc}
\hline \multirow{2}{*}{ ITG_MDT } & $\begin{array}{l}\text { mean } \\
\sigma_{\mathrm{MDT}}\end{array}$ & CLS09 & DTU10 & Niiler & CLS09 & DTU10 & Niiler \\
\cline { 3 - 7 } & $0.162 \mathrm{~m}$ & $0.186 \mathrm{~m}$ & $0.176 \mathrm{~m}$ & $0.174 \mathrm{~m}$ & 0.800 & 0.776 & 0.841 \\
\hline $\begin{array}{l}\text { overall } \\
\text { profile }\end{array}$ & $0.147 \mathrm{~m}$ & $0.134 \mathrm{~m}$ & $0.136 \mathrm{~m}$ & $0.141 \mathrm{~m}$ & 0.730 & 0.749 & 0.822 \\
$\begin{array}{l}44.5^{\circ} \mathrm{W} \\
\text { profile }\end{array}$ & $0.156 \mathrm{~m}$ & $0.149 \mathrm{~m}$ & $0.129 \mathrm{~m}$ & $0.135 \mathrm{~m}$ & 0.692 & 0.680 & 0.729 \\
$\begin{array}{l}20.5^{\circ} \mathrm{W} \\
\text { profile }\end{array}$ & $0.168 \mathrm{~m}$ & $0.278 \mathrm{~m}$ & $0.241 \mathrm{~m}$ & $0.207 \mathrm{~m}$ & 1.056 & 0.973 & 1.075 \\
$70.5^{\circ} \mathrm{W}$ & & & & & & & \\
\hline
\end{tabular}

\begin{tabular}{|c|c|c|c|c|c|c|}
\hline \multirow{2}{*}{ IFEOM } & \multicolumn{3}{|c|}{ IFEOM_MDT: RMS } & \multicolumn{3}{|c|}{ IFEOM first guess: RMS } \\
\hline & CLS09 & DTU10 & Niiler & CLS09 & DTU10 & Niiler \\
\hline overall & $0.081 \mathrm{~m}$ & $0.062 \mathrm{~m}$ & $0.067 \mathrm{~m}$ & $0.124 \mathrm{~m}$ & $0.088 \mathrm{~m}$ & $0.083 \mathrm{~m}$ \\
\hline $\begin{array}{l}\text { profile } \\
44.5^{\circ} \mathrm{W}\end{array}$ & $0.074 \mathrm{~m}$ & $0.055 \mathrm{~m}$ & $0.055 \mathrm{~m}$ & $0.118 \mathrm{~m}$ & $0.090 \mathrm{~m}$ & $0.079 \mathrm{~m}$ \\
\hline $\begin{array}{l}\text { profile } \\
20.5^{\circ} \mathrm{W}\end{array}$ & $0.055 \mathrm{~m}$ & $0.032 \mathrm{~m}$ & $0.070 \mathrm{~m}$ & $0.062 \mathrm{~m}$ & $0.044 \mathrm{~m}$ & $0.055 \mathrm{~m}$ \\
\hline \multirow[t]{3}{*}{$\begin{array}{l}\text { profile } \\
70.5^{\circ} \mathrm{W}\end{array}$} & $0.138 \mathrm{~m}$ & $0.099 \mathrm{~m}$ & $0.116 \mathrm{~m}$ & $0.225 \mathrm{~m}$ & $0.137 \mathrm{~m}$ & $0.115 \mathrm{~m}$ \\
\hline & \multicolumn{3}{|c|}{ RMS } & & & \\
\hline & $\begin{array}{l}\text { CLS09/ } \\
\text { DTU10 }\end{array}$ & $\begin{array}{c}\text { CLS09/ } \\
\text { Niiler }\end{array}$ & $\begin{array}{c}\text { DTU10/ } \\
\text { Niiler }\end{array}$ & & & \\
\hline overall & $0.081 \mathrm{~m}$ & $0.078 \mathrm{~m}$ & $0.052 \mathrm{~m}$ & & & \\
\hline $\begin{array}{l}\text { profile } \\
44.5^{\circ} \mathrm{W}\end{array}$ & $0.050 \mathrm{~m}$ & $0.054 \mathrm{~m}$ & $0.026 \mathrm{~m}$ & & & \\
\hline $\begin{array}{l}\text { profile } \\
20.5^{\circ} \mathrm{W}\end{array}$ & $0.068 \mathrm{~m}$ & $0.100 \mathrm{~m}$ & $0.051 \mathrm{~m}$ & & & \\
\hline $\begin{array}{l}\text { profile } \\
70.5^{\circ} \mathrm{W}\end{array}$ & $0.120 \mathrm{~m}$ & $0.140 \mathrm{~m}$ & $0.075 \mathrm{~m}$ & & & \\
\hline
\end{tabular}

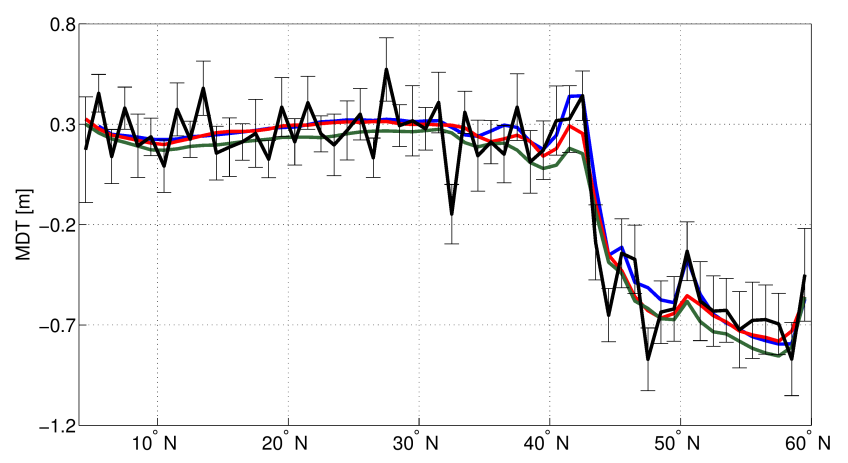

Fig. 4 Profile of MDT estimates along the meridian $44.5^{\circ} \mathrm{W}$ : CLS09 (blue), DTU10 (red), Niiler (green), ITG_MDT with error bars (black).

a measure of consistency

$$
\begin{aligned}
& R_{I}=\overline{\left(\frac{\left|\mathrm{ITG}_{-} \mathrm{MDT}-\mathrm{MDT}_{I}\right|}{\sigma_{\mathrm{MDT}}}\right)}, \\
& I=\text { CLS09, DTU10, or Niiler, }
\end{aligned}
$$

for all of the North Atlantic Ocean and for three different profiles. The results are summarized in table 2 . Additionally, the mean standard deviation of the mean dynamic topography for the respective area is shown.

For the sum of all IFEOM grid points, the smallest RMS value can be observed with the Niiler model, while the mean relative difference is the smallest with the DTU10 model. In all cases, the root mean square of the differences is larger than mean standard deviation of the MDT, but the mean relative differences remain below 1 for the complete study area. As indicated by the respective values for the different profiles, the results of the model comparisons vary over the study area.

The largest differences can be found within the profile along the meridian $70.5^{\circ} \mathrm{W}$ with a root mean square always exceeding $20 \mathrm{~cm}$. Here, the standard deviation of the estimated MDT is smaller than the derived RMS as opposed to the other profiles. The mean relative dif- 
ferences are also largest at this profile. These large differences are related to the large coastal areas within this profile, where the separation of the altimetric mean sea surface into geoid and dynamic topography is most challenging. If the nodal points nearest to the coastlines are excluded from the computations, the mean standard deviation and the root mean square of the differences decrease to values similar to those for the other profiles with a magnitude of $14 \mathrm{~cm}$. The mean relative differences also decrease and reach a magnitude of 0.8 .

Furthermore, the comparison models obviously are not error free. To accomplish an objective comparison, these errors also need to be taken into account. In fact, the three models remarkably differ from each other. The particular RMS values for the corresponding differences are also shown in table 2 .

The ITG_MDT tends to have stronger small scale and large scale gradients than the comparison models. Stronger gradients imply a locally faster circulation with narrow currents. These can only be resolved properly with sufficiently high resolution in both altimetry and gravity data and the appropriate combination of these data with a minimum of signal loss. The faster circulation will also be discussed in Section 4.2.

In conclusion, the comparison findings depend on the particular considered region. The derived mean dynamic topography model ITG_MDT does not tend towards one specific comparison model. In general, the ITG_MDT agrees with at least one of the other models within the error description having in mind that these models also contain uncertainty.

\subsection{Impact of the geodetic MDT on the IFEOM estimate}

The geodetic mean dynamic topography model ITG_MDT constructed in the previous sections is combined with IFEOM as outlined in section 3.1. The additional data changes the IFEOM solution and the effect of these changes are discussed in this section.

Figure 5(a) shows the mean dynamic topography estimated by IFEOM without the new ITG_MDT (the first guess). In figure 5(b) the new ITG_MDT has been included to obtain a new circulation estimate, which we label IFEOM_MDT. The difference between these two MDTs is plotted in figure 5(c).

Naively one expects a compromise of the first guess (Figure 5(a)) and the geodetic ITG_MDT in Figure 3, but the combination in Figure 5(b) is more than that. The new solution reproduces many of the sharp features of the geodetic ITG_MDT, for example, the strong gradient across the Gulf Stream along $40^{\circ} \mathrm{N}$, the extension of the sub-polar gyre along the North American coast to Cape Hatteras near $35^{\circ} \mathrm{N}$, and the Mann eddy near $\left(40^{\circ} \mathrm{W}, 40^{\circ} \mathrm{N}\right)$. The subpolar gyre is stronger in the combination solution. At the same time the small scale noise of the geodetic ITG_MDT does not appear in the combination implying that the unphysical properties of the geodetic ITG_MDT are rejected by IFEOM, in part because the weighting matrix contains appropriate smoothness information. As a result the IFEOM_MDT is always more similar to the comparison models than the IFEOM first guess MDT and the geodetic ITG_MDT (table 2). As a matter of fact, the root mean square of differences between the IFEOM_MDT and the comparison models is of the same order of magnitude and even smaller than those between the comparison models (table 2).

In part, the smooth combination solution is a consequence of the smoothness constraints and the smooth hydrography in IFEOM, but some of the smoothness is imposed by the weighting matrix, that is, the inverse covariance matrix in equation (9). This is illustrated in a sensitivity run of IFEOM with a weighting matrix, where all off-diagonal terms have been set to zero. Figure $5(\mathrm{~d})$ shows that the difference between the solution with the full weighting matrix and this solution, which represents the impact of the off-diagonal elements on the estimation 5(b), contains a lot of the small scale noise that is also visible in figure 3 . Note, that the differences illustrated in figures $5(\mathrm{c})$ and $5(\mathrm{~d})$ show a similar pattern, however, with a different order of magnitude. The off-diagonal terms remarkably contribute to the IFEOM_MDT especially along the gulf stream.

The noise suppression becomes even more apparent in a plot of the MDT along a meridian at $44.5^{\circ} \mathrm{W}$ (figure 4.2). The too small large-scale gradients of the first guess solution (in red) have been adjusted to fit the observations, but the grid-scale flucations of the ITG_MDT (in black) are not visible in the combination solution (in blue). Still, features only slightly larger than the grid scale emerge in the combination solution, for example, the Mann eddy between $40.5^{\circ} \mathrm{N}$ and $42.5^{\circ} \mathrm{N}$.

IFEOM's circulation and hydrography is modified by including the geodetic ITG_MDT. Figure 7 shows the zonal mean of the temperature and salinity adjustments (i.e. the difference between the solution and the first guess). Particularly, near $40^{\circ} \mathrm{N}$ temperature is increased over the top $800 \mathrm{~m}$, but also the deep ocean is affected by the surface data. The change in temperature explains most $(40-50 \mathrm{~cm})$ of the change in MDT along the Gulf Stream between $80^{\circ} \mathrm{W}$ and $40^{\circ} \mathrm{W}$ as a thermosteric effect $\left(\Delta \eta_{\text {thermosteric }}=-\int \alpha \Delta T d z\right.$, with the thermal expansion coefficient $\alpha$ ). The halosteric effect $\left(\Delta \eta_{\text {halosteric }}=\int \beta \Delta S d z\right.$, with the haline contraction 


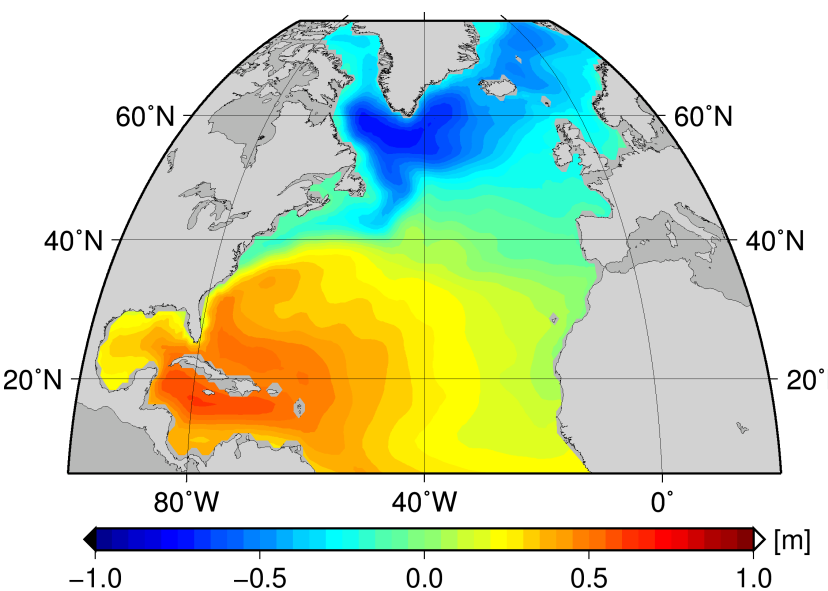

(a)

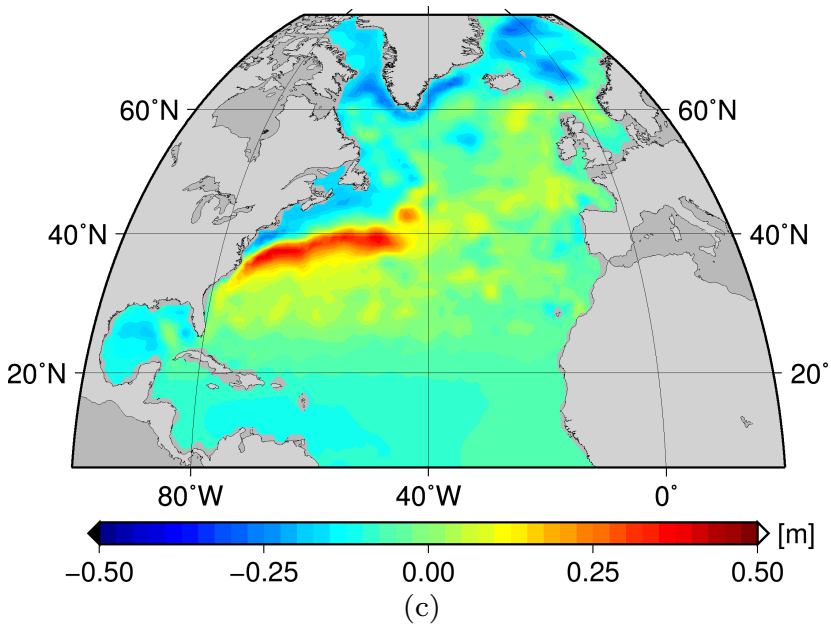

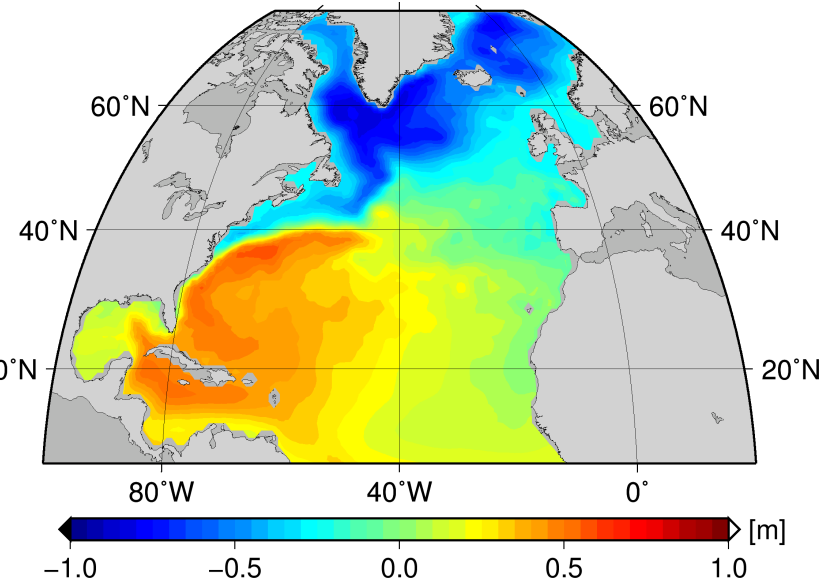

(b)

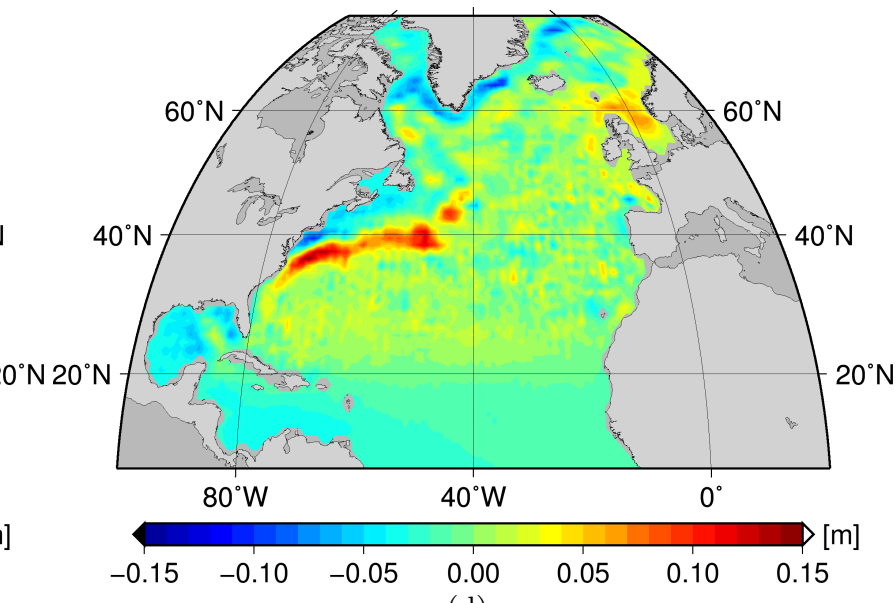

(d)

Fig. 5 IFEOM estimates of mean dynamic topography (a) from hydrography alone; (b) additionally with the geodetic MDT; (c) difference of (b)-(a); (d) difference between (b) and a run where all off-diagonal weights for the MDT have been set to zero.

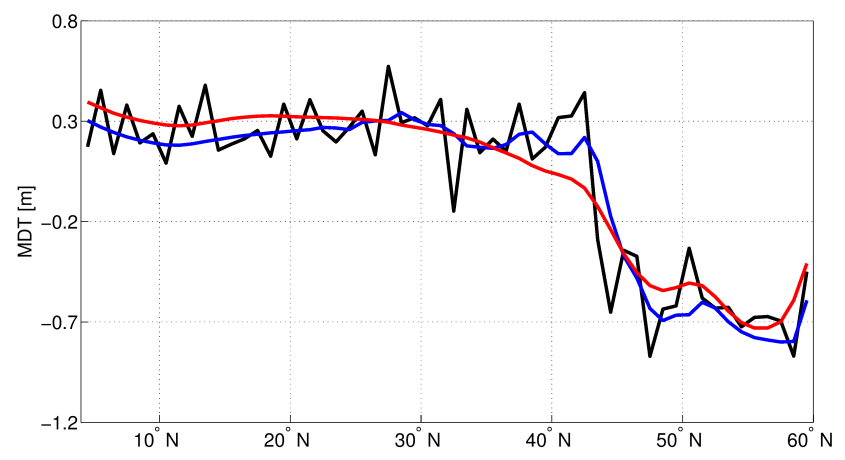

Fig. 6 MDT estimates along the meridian $44.5^{\circ} \mathrm{W}$ : IFEOM first guess (red), IFEOM estimate with geodetic ITG_MDT (blue), ITG_MDT (black).

coefficient $\beta$ ) is smaller in this region but adds another 5-15 cm to explain the rest of the MDT increase. The increased salinity between $50^{\circ} \mathrm{N}$ and $60^{\circ} \mathrm{N}$ reflects ha- line contraction to produce a deeper MDT minimum in the subpolar gyre (cf. figure 5(b)) with a stronger circulation. Further, the reduced buoyancy (increased salinity) favors vertical convection and leads to more meridional overturning circulation in the model as discussed in Becker et al (2012). The modified hydrography has a profound effect on other properties of the solution, for example the oceanic heat transport.

Poleward oceanic heat transport is about half of the total poleward heat transport up to $28^{\circ} \mathrm{N}$ after which it drops to much lower values (Wunsch, 2005). Even these low numbers represent an important contribution to the net heat budget. Figure 8 shows the oceanic heat transport estimated by IFEOM with and without the new geodetic ITG_MDT; also shown are independent estimates obtained from individual hydrographic cruises across the Atlantic Ocean and a previous estimate by Becker et al (2012). After adjusting to the geodetic ITG_MDT, the heat transport in IFEOM has changed 

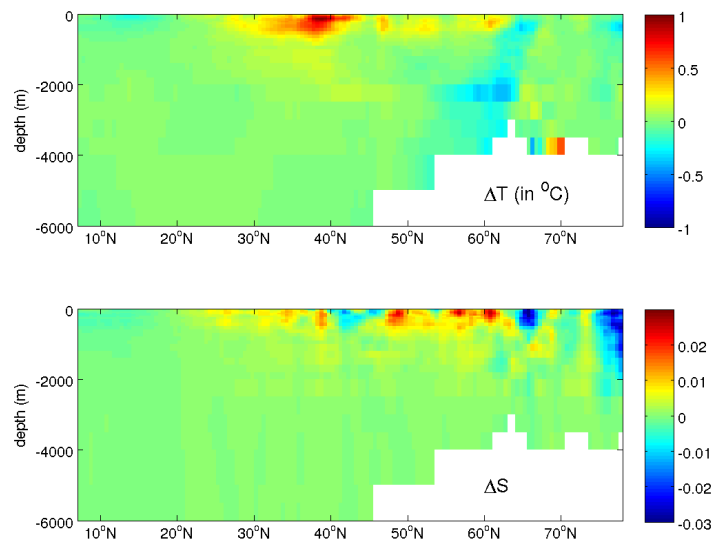

Fig. 7 Zonally averaged difference in temperature (top) and salinity (bottom) between the solution with geodetic ITG_MDT and the first guess.

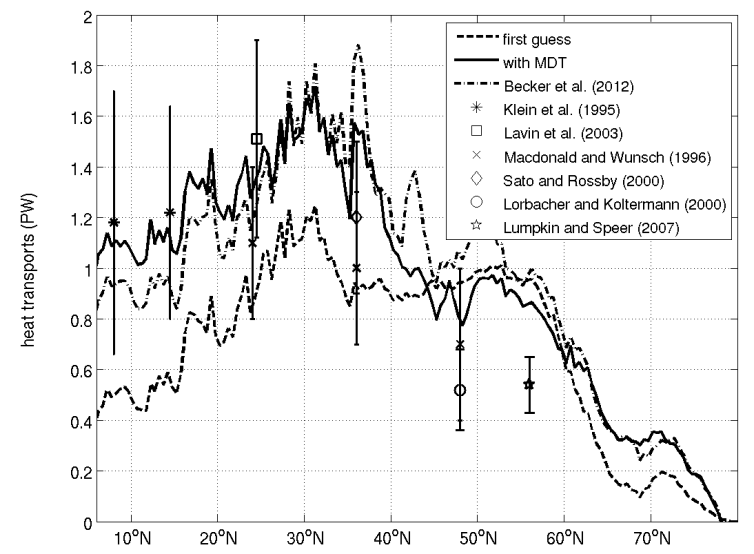

Fig. 8 IFEOM heat transport (PW) as a function of latitude and independent estimates with error bars.

towards a better agreement with all cited previous estimates except for the estimates of Macdonald and Wunsch (1996) who estimate lower heat transports at $24^{\circ} \mathrm{N}$ and $36^{\circ} \mathrm{N}$. Compared to the previous IFEOM solutions presented in Becker et al (2012, their figure 10, solution IFEOM03) the solution with the new improved geodetic ITG_MDT appears more realistic, as the heat transport does not have the isolated spikes near $36^{\circ} \mathrm{N}, 43^{\circ} \mathrm{N}$, and $51^{\circ} \mathrm{N}$, that were caused by including observationally unresolved scales in the previous MDT estimate. Note, that the previously presented results in Becker et al (2012) were based on an absolutely different model configuration regarding the data sets (gravity field model ITG-Grace2010s (Mayer-Gürr et al, 2010), mean sea surface model MSS_CNES_CLS10 (MSS_CNES_CLS10, 2010 ) extracted on a $0.5^{\circ} \times 0.5^{\circ}$ grid without consider- ing correlations), the finite element grid $\left(2^{\circ} \times 2^{\circ}\right.$ grid instead of the $1^{\circ} \times 1^{\circ}$ grid used in this study), the modeling of the omission domain (consideration of prior information from the EGM2008 signal and error variances) and the maximum spherical harmonic degree.

\section{Discussion and conclusion}

Previous methods of combining space-borne gravity data and altimetric sea surface height observation suffer from various drawbacks that we have overcome by presenting a complete and consistent end-to-end processing chain from the original measurements to the final product.

We calculated a profile of mean sea surface heights from along-track altimetric observations including a rigorous variance propagation based on empirical error modeling, so that, for the first time, the full error covariance matrix of the mean sea surface is available and incorporated in the estimation of the mean dynamic topography. Within the developed integrated approach the observation groups are consistently combined in terms of normal equations accounting for both instrumental and omission errors. Relative weights between the different observation groups are determined by an objective method, a variance component estimation. No explicit filter or smoothness constraints are applied to the mean dynamic topography parameters, avoiding unspecified signal loss. The full signal content of the observations is contained in the estimated geodetic mean dynamic topography.

The apparent drawback of this approach is potentially noise in the signal field. The noise level depends on the resolution of the target grid generally in relation to the gravity data resolution, but the error covariance also reflects the noise in a consistent way. The crucial point is, that the presented method is tailored to the integration into ocean circulation models; i.e. the MDT itself is not designed for further studies without consideration of the corresponding covariance matrix. Weighting the data with the inverse of the error covariance removes the noise from the signal. In this sense, the signal field and weighting matrix form an entity that must be used in combination.

The main technical advantage of the MDT model is that it can be directly combined with inverse ocean models, because the mean dynamic topography along with the inverse error covariance matrix is directly estimated on the target grid. The procedure leads to selfconsistent mean dynamic topography estimates that can readily be assimilated into complex numerical ocean models, because the associated weight matrices provide essential information about the reliability of the MDT estimates to the ocean model in a form that requires no 
further processing. All available information has been exploited optimally to arrive at this MDT estimate.

In this study, the inverse ocean circulation model IFEOM predefines the target grid. The resulting geodetic ITG_MDT (figure 3(a)) contains the large scale surface features of ocean dynamics. Near-grid-scale gradients are also visible in the solution, but they are overlaid by grid-scale noise because the gravity field model do not provide sufficiently accurate information on this particular grid. Note that the unphysical nature of the grid scale noise is reflected in similar patterns in the error covariance giving the noisy scales smaller weights in the inversion.

On spatial scales, where all observations provide accurate information, the altimetric data can be separated very well into geoid and MDT. The integration of the ITG_MDT into IFEOM indicates the success of the approach. Because of the structure of the weight matrix, and in particular its off-diagonal elements, the noise in ITG_MDT is rejected by the ocean model while large-scale oceanic features in the ITG_MDT are retained. The combination of ITG_MDT, oceanic data, and dynamic constraints leads to a smooth, physically plausible mean dynamic topography.

Acknowledgements This work was funded within the DFG priority programme SPP 1257 "Mass transport and mass distribution in the system Earth". Since 2013 the first author is co-financed by ESA within ESA's Support To Science Element programme. The computations were performed on the JUROPA supercomputer at FZ Jülich. The computing time was granted by John von Neumann Institute for Computing (project HBN15). We thank Dmitry Sidorenko for indispensible help with IFEOM.

\section{References}

Andersen O, Knudsen P (2009) DNSC08 mean sea surface and mean dynamic topography models. Journal of Geophysical Research 114:C11,001, DOI 10.1029/ 2008JC005179

AVISO (2008) AVISO and PODAAC User Handbook, IGDR and GDR Jason Products. http: //www . aviso.oceanobs. com/fileadmin/ documents/data/tools/hdbk_j1_gdr.pdf

Becker S (2012) Konsistente Kombination von Schwerefeld, Altimetrie und hydrographischen Daten zur Modellierung der dynamischen Ozeantopographie. PhD thesis, Universität Bonn, http://hss.ulb. uni-bonn.de/2012/2919/2919.htm

Becker S, Freiwald G, Losch M, Schuh WD (2012) Rigorous fusion of gravity field, altimetry and stationary ocean models. Journal of Geodynamics 59-60:99-110, DOI 10.1016/j.jog.2011.07.0069
Becker S, Brockmann J, Schuh WD (2013) Consistent combination of gravity field, altimetry and hydrographic data. In: Willis $\mathrm{P}$ (ed) Procceedings of the International Symposium on Gravity, Geoid and Height Systems (GGHS2012), IAG Symposia, Springer Berlin Heidelberg (accepted)

Bingham RJ, Haines K, Hughes CW (2008) Calculating the ocean's mean dynamic topography from a mean sea surface and a geoid. Journal of Atmospheric and Oceanic Technology 25, DOI 10.1175/ 2008JTECHO568.1

Bosch W, Savcenko R (2010) On estimating the dynamic ocean topography a profile approach. International Association of Geodesy Symposia 135:263-269, DOI 10.1007/978-3-642-10634-7_34

Brockmann JM, Schuh WD (2010) Fast variance component estimation in GOCE data processing. In: Mertikas S (ed) Gravity, Geoid and Earth Observation, IAG Symposia, Springer Berlin Heidelberg, DOI 10.1007/978-3-642-10634-7_25

Freiwald G (2012) Combining stationary ocean models and mean dynamic topography data. $\mathrm{PhD}$ thesis, Universität Bremen, Bremen, URL http://nbn-resolving.de/urn:nbn:de:gbv: 46-00102742-13

Gouretski VV, Koltermann KK (2004) WOCE global hydrographic climatology. Berichte des Bundesamtes für Seeschifffahrt und Hydrographie, Nr. 35, http://www.bsh.de/de/Produkte/Buecher/ Berichte_/Bericht35/index.jsp

Hernandez F, Schaeffer P (2001) The CLS01 mean sea surface: A validation with the GSFC00.1 surface. report, 14 pp, CLS, Ramonville, St Agne, France

Kaula WM (1966) Theory of Satellite Geodesy. Blaisdell Publ. Comp., Massachusetts-Toronto-London

Klein B, Molinari R, Müller T, Siedler G (1995) A transatlantic section at $14.5^{\circ} \mathrm{N}$ : Meridional volume and heat fluxes. Journal of Marine Systems 53:929957

Knudsen P, Bingham R, Andersen O, Rio MH (2011) A global mean dynamic topography and ocean circulation estimation using a preliminary GOCE gravity model. Journal of Geodesy DOI 10.1007/ s00190-011-0485-8

Koch KR (1999) Parameter Estimation and Hypothesis Testing in Linear Models. 2. edition, Springer, Berlin, Heidelberg

Koch KR, Kusche J (2002) Regularization of geopotential determination from satellite data by variance components. Journal of Geodesy 76:259-268, DOI 10.1007/s00190-002-0245-x

Lavín A, Bryden HL, Parrilla G (2003) Mechanisms of heat, freshwater, oxygen and nutrient transports and 
budgets at $24^{\circ} \mathrm{N}$ in the Subtropical North Atlantic. Deep-Sea Research I 50:1099-1128

Lorbacher K, Koltermann P (2000) Subinertial variability of transport estimates across $48^{\circ} \mathrm{N}$ in the North Atlantic. International WOCE Newsletter 40:3-5

Losch M, Sloyan B, Schröter J, Sneeuw N (2002) Box inverse models, altimetry and the geoid: Problems with the omission error. Journal of Geophysical Research 107(C7), DOI 10.1029/2001JC000855

Lumpkin R, Speer KG (2007) Global ocean meridional overturning. Journal of Physical Oceanography 37(10):2550-2562, DOI 10.1175/JPO3130.1

Macdonald AM, Wunsch C (1996) An estimate of the global ocean circulation and heat flux. Nature 382:436-439

Maximenko N, Niiler P, Rio MH, Melnichenko O, Centurioni L, Chambers D, Zlotnicki V, Galperin B (2009) Mean dynamic topography of the ocean derived from satellite and drifting buoy data using three different techniques. Journal of Atmospheric and Oceanic Technology 26:1910-1918, DOI 10.1175/ 2009JTECHO672.1

Mayer-Gürr T, Kurtenbach E, Eicker A (2010) ITGGrace2010 gravity field model. http://www.igg. uni-bonn .de/apmg/index .php?id=itg-grace2010

MSS_CNES_CLS10 (2010) MSS_CNES_CLS10 was produced by CLS Space Oceanography Division and distributed by Aviso, with support from Cnes (http: //www . aviso. oceanobs. com/).

Pail R, Bruinsma S, Miggliaccio F, Förste C, Goiginger H, Schuh WD, Höck E, Reguzzoni M, Brockmann J, Abrikosov O, Veicherts M, Fecher T, Mayrhofer R, Krasbutter I, Sansó F, Tscherning C (2011) First GOCE gravity field models derived by three different approaches. Journal of Geodesy 85(11):819-843, DOI 10.1007/s00190-011-0467-x

Pavlis N, Holmes S, Kenyon S, Factor J (2012) The development and evaluation of the Earth Gravitational Model 2008 (EGM2008). Journal of Geophysical Research 117, DOI 10.1029/2011JB008916

Richter F (2010) Nutzung von Argo-Driftern und Satellitenaltimetriedaten zur Ableitung der Zirkulation im Nordatlantik. PhD thesis, Universität Bremen

Rio MH, Guinehut S, Larnicol G (2011) New CNESCLS09 global mean dynamic topography computed from the combination of grace data, altimetry, and in situ measurements. Journal of Geophysical Research 116:C07,018, DOI 10.1029/2010JC006505

Sato OT, Rossby T (2000) Seasonal and low-frequency variability of the meridional heat flux at $36^{\circ} \mathrm{N}$ in the North Atlantic. Journal of Physical Oceanography 30(3):606-621
Schuh WD, Becker S (2010) Potential field and smoothness conditions. In: Contadakis M, Kaltsikis C, Spatalas S, Tokmakidis K, Tziavos I (eds) The apple of knowledge - In honour of Prof. N. Arabelos, University of Thessaloniki, AUTH - Faculty of rural and surveying engineering, pp $237-250$

Schuh WD, Becker S, Brockmann J (2013) Completion of band-limited data sets on the sphere. In: Kutterer H, Seitz F, Alkhatib H, Schmidt M (eds) Proceedings of the 1st international Workshop on the Quality of Geodetic Observations and Monitoring Systems (QuGOMS'11), IAG Symposia, Springer Berlin Heidelberg (accepted)

Sidorenko D (2004) The North Atlantic circulation derived from inverse models. $\mathrm{PhD}$ thesis, Universität Bremen

Wunsch C (2005) The total meridional heat flux and its oceanic and atmospheric partition. Journal of Climate 18(21):4374-4380, DOI 10.1175/JCLI3539.1 